Oribasius (A.D. 360), states that calculi are due either to drinking turbid water or to imperfect digestion.

Aëtius $^{5}$ (sixth century) gives a full exposition of the views of the ancient physicians and furnishes very exact details regarding treatment. He shows that abscess of the kidney is very liable to lead to fistula, and that it is difficult or impossible to heal. He indicates some of the causes of bleeding from the kidneys: "According as it arises in those who have lifted a heavy weight, or have jumped vigorously, or fallen from a height, or undergone some other similar violent shock."

During the dark ages the physicians satisfied themselves by learning what the Greek and Arabian authors tanght until through time they came to believe that Hippocrates, Galen, Ptolemy, and Aristotle had finally settled all scientific questions and that to doubt their decisions was heresy. Respecting operations on the kidney Galen's teaching was believed in rather than that of Hippocrates or Ruffus, and consequently the surgical treatment of snppurative disease of the kidney dropped into obscurity. Little advance was made in the pathology of renal disease until the seventeenth century, when the practicability of operating upon the kidney again came to be discussed. The subject was approached, however, at that time more from the philosophical than from the scientific standpoint; later, pathological anatomy furnished new means of research.

(To be continued.)

\section{AD TERRAM.}

By Sir Francis Seymour Haden, F.R.O.S. Eng.

\section{The Earth and The Soll.}

I HAD hoped, after the record which you were good enough to enable me to make in THE LANCET of May 27th, 1899 , p. 1411, of $\mathrm{my}$ views as to the competency of the earth, properly treated, to deal effectively and harmlessly with all forms of organic decay returning in the course of nature to its surface, that I should not again have to trouble you on the subject; nor should I be doing so now if continued investigations had not satisfied me that we hold in our own hands a key to other equally great truths which in our engrossing pursuit of the microbe we have allowed to escape us-a key, also, which, if applied with a firmer faith in the ordinary operations of nature than we seem just now disposed to accord them, I would fain hope may one day win us back to those larger methods of Inductive Research which we associate with the name of Bacon, and to which, indeed, we owe, directly or indirectly, nearly every great discovery that we have made our own since his time.

It is, however, not alone to regret our growing tendency to break away, on grounds which I must think wholly speculative, from the surer methods of the Baconian philosophy, that I am again venturing to address you, but rather to invite the attention of the profession to the experiments we are making and the language we are employing to chronicle their results-experiments which, since we are making them not in the earth, but in the soil which covers the earth, do nothing to prove the latter the hotbed of infection which some would have us believe it to be, but rather suggest one of two things-either that we are failing to recognise the real nature of the medium we are employing in our investigations, or, which is even more likely, that we are taking it for granted that the soil and the earth are one and the same thing, whereas, from the point of view of the present article, not only are they not the same thing, but, in all but the equal and independent share which they have in the conversion of effete organic matter into its elements, two essentially different bodies-different in their origin, different in their nature, and different in the parts which they play in the world's economy.

Nor is there, I would respectfully submit, any room to donbt the prevalence of the additional oversight which we are thus making, since evidence of that tendency confronts us at every turn-in our choice of the soil as a medium in which to make our experiments, a medium in which we may, if so minded, cultivate anything from a microbe to a mush room; in the adoption of a terminology, fast degenerating into a vernacular, which is intelligible only to those of us who are content to live under the exacting dispensation of the microbe; in our lectures, our correspondence, our reports, and even in our text-books, which, one and all so far as I can see, speak of the earth as a sort of composite body which they describe as "the soil," or it may even be, when put to it for a pseudonym, as the "subsoil." Thus, we are in no way surprised when so accurate an observer as Professor G. T. Poore ${ }^{1}$ candidly tells us that when he speaks of "earth" he means "humus" (which is soil), or when so practical and conscientious an experimentalist as Dr. Klein" uses the term "earth" in the same sense as his equally careful fellow-reporter, Dr. A. C. Houston, ${ }^{3}$ uses the word "soil" ; or finally, since it is useless to recapitulate examples of the same thing, when my courteous critic and mentor, Sir Charles Cameron of Dublin ${ }^{4}$ referring to "gravels and boulder clays" (which are earths) calls them "soils," and even goes out of his way to emphasise the kindly lesson he is readung me, by a formal record of his belief that "the cleaner the soil we live on the longer we shall live on it." But the soil which I am speaking of is never clean, never has been clean since the globe became populated, and never will be clean till it reverts to the sterility which there is every reason to believe at one time affected it

The soil, in fact, according to experiments which have been now uninterruptedly carried on at Woodcote for 14 years, and which, though still incomplete on one or two points, I consider fully warrant the crude results I am now giving of them, is "soil" in the most ordinary acceptation of the word-orgaric refuse, that is, animal as well as vegetable, which having lived its life and served its purpose on the outermost confines of the globe has dropped out of existence and, in obedience to a law which neither it nor any other material body is able to resist, is already when we meet with it on its way towards its centre of gravity. Soil, in fact, according to my understanding of it, is manure - the very medium in which with so much confidence we are making our experiments-the one great fertilising agent without which the earth would starve, its populations die out, and the atmosphere itselfdeprived as it would then be of its means of renewal and consequently without a purpose-not impossibly also cease to exist.

The earth, on the other hand, properly so-called (from my point of view), is the very opposite of all this. While the soil is organic the earth is inorganic. While the soil has its origin on the periphery of the globe, the earth has its origin in its own centre, and its earliest developments in the breaking up and gradual disintegration (by a variety of forces, the nature of which being well understood I need not here dwell upon) of its own primitive rocks, till at last they are reduced to the friable matter which we know as "earth." Again, as to the comparative age of the two bodies; while that of the soil can in no case exceed the age of the animal which produces it, or in the case of vegetables the duration of the seasonal intervals which mark the rotation of crops, the fall of the leaf, and so forth, the age of the earth is measurable only by the countless ages during which we know it to have been in course of formation. And yet, again, separated as the two bodies originally are by a space as great as that which separates the poles from the equator, and approaching each other-as, in a sense, they may be said to do-from opposite ends of the earth, they have, and can have, nothing in common till by a provision of nature (gravitation) they are brought into actual contact; a contact differing in nothing, so far as I can see, from that of any two bodies which, being chemically incompatible, give rise on their admixture to a change of their elements, and it may even be to the creation of a new force-such a force, for instance, as has its analogue in the production of the electric spark by the contact of the opposite poles of the voltaic pile. For the interposition of the microbe in changes and metamorphoses of this kind I must confess that I can see no necessity whatever, or, in fact, for that of any foreign body, saprophytic, bacterial, or otherwise cryptic and gratuitous.

The physical properties of the soil, again, its weight, its

1 First Milroy Lecture, THE LanceT, Feb. 25tb, 1899, p. 491.

2 Report (to the Local Government Board, 1898-99) on the Fate of Pathogenic and other Infective Microbes in the Dead and Buried Bodv (in "earth") pp. 344-360 et, passim-372.

3 Report (to the Local Government Board, 1898-99) on the Inoculation of the Soil with Particular Mierobes, p. 413.

4. The Soil as a Nursery of Pathogenie Organisms, June 3rd, 1899, p. 1374 . 
volume, and its extraordinary value as a fertilising agent, will, from what has been said of its nature and origin, be readily understood to be measurable only by the whole extent of the earth's surface (which it more or less entirely covers and overlies) and by the amount of organic life, animal as well as vegetable, which is its immediate source of supply. Then, as to its weight and the pressure which it exercises on the earth's surface (as to which I shall have more to say later) it is, of course, that of the atmosphere plus its own density and the weight represented by the pressure which it exercises on the earth's surface as the effect of gravitation. It is, however, its vast extent, its kind, and the irregularity of its distribution which, for the purposes of this communication, chiefly concern us.

Experiments made in the laboratory have, meanwhile, told us nothing on these points, and herein must be my apology for the nonconformity of my views with those of the eminent men who-taking the microbe for granted and making it the basis of their inquiries-have been generally received as authorities on that part of the subject; the difference between us, however, depending, I think, mainly on the fact that while their investigations have for the most part been founded on experiments made within doors, and on the strength of pre-arranged lines of inquiry, mine have been made wholly out of doors and on lines suggested simply by what I have met with and seen there during a continuous succession of observations which have engaged much of my attention for 25 years and pretty nearly the whole of it for the last 14 years.

So much for a theory merely in outline and as yet with such proofs only of its stability as may reasonably be read between the lines of the present communication. Nothing will be easier than, at the proper time, to multiply such proofs, at all events to the extent of largely extending and strengthening the ground on which that stability rests. On the other hand, points have yet to be cleared up which, though by no means obscure, require time for their elucidation, and which make me unwilling to go to print with them till 1 have had that time at my disposal. A single example of such points will suffice to explain this indisposition on my part. Though I have long been aware that nitrification is a more rapid process than $I$ once believed it to be, I had no idea till lately how much more rapid a process it really is; nor, though I have now no doubt of the fact, have I yet been able to arrive at anything like its exact measure.

Again, though I have been making my graves under various conditions as to depth and the contiguity of their contents with the earth enclosing them-beginning with a depth of four feet, as that prescribed by the Local Government Board, and ending by simply laying the body on the ground and covering it over with a single foot of earth-my examinations of the whole of these graves have only been made once a year and the results of such examinations only recorded in print once a year; I now know that if I had examined them every half-year I should have found, I will not say the same astonishing results, but evidence of a far more rapid progress towards a return of the body to its elements than I had then believed possible, as well as arrived at a more exact knowledge of the rate and kind of change undergone by the body in the interval.

The solution of such a moot point is, of course, of the highest practical importance, and I am led by it to the conclusion that, rather than present such a point in an imperfect form, I shall do well to let the present paper go to press as it is and return to it later.

The New Operating Theatre for the Royal In FIRnari, Preston. - The new theatre which by the generosity of Dr. R. C. Brown, of Preston, has just been completed and equipped at a total cost of $\$ 2654$ is in many respects a model building. It is situated in the centre of the infirmary blocks and is built of iron, glass, and tiles. Every precaution has been taken to dispense with corners and angles and the building is so constructed that it can be effectively cleansed with a hose. It is surmounted by a double roof in order that an equable temperature may be obtained at all seasons of the year. The theatre is well lighted by electric light and there is a specially large north window eight feet wide and six feet high. Nothing that could be done has been left undone to make the new operating theatre, of which Pres' on must be proud, as perfect as possible from every point of view, and the inhabitants of that town owe a deep debt of gratitude to Dr, Brown.

\section{THE ROYAL COMMISSION ON SOUTH AFRICAN HOSPITALS.}

(Continued from p. 575.)

\section{II.}

PART IIL. of the Commissioners' report is taken up with a detailed investigation of the various complaints made as to the cale of the sick and wounded during the campaign and the conclusions arrived at in respect of such complaints. The subject is studied in the following order as regards the care taken and the various complaints which bave arisen, Natal anā all places not in Cape Colony, the Orange River Colony, or the Transvaal being excluded from consideration here.

(A) At the front, including some places which are conveniently dealt with under this head, such as Kimberley, Modder River, Driefontein or Abram's Kraal, Bloemfont ein, Kroonstad, Johannesberg, and or Abram's Kraal, Bloemfont ein, Kroonstad, Johannesberg, and Pretoria; (B) in the conveyance of patients to and from fixed bospitals
on the lines of communication and at the base; (C) at the hospitals on on the lines of communication and at the base; (C) at the hospitals on
the lines of communication; and (D) at the hospitals at the base, the lines of communication ; and (D) at
including the hospital transport ships. ......

\section{A.-Aт THe Front.}

The details of this class group themselves and can be best dealt with under the following heads:-(1) the advance of Lord Methuen to the relief of Kimberley; (2) the advance of Lord Roberts to Kimberley and to Bloemfontein ; (3) Bloemfontein during Lord Roberts's stay there before his subsequent advance and afterwards; (4) the advance from Bloemfontein to Kroonstad : (5) Krounstad ; (6) Johannesberg and the advance from Kroonstad ; (7) Pretoria; and (8) concluding remarks as to the care of the sick and wounded at the front. Outside these group there are but few matters relating to the condition of affairs at the front which require attention beyond our general observations in Part II., and so far as these few matters appear to us to need special mention we have dealt with them at the end.

The present article only deals with the first three sections of sub.heading A, the hospital question being, as all our readers know, particularly acute at Kimberley.

\section{Methuen's AdVANCE To Kimberley.}

With regard to $A$ (1) the Commissioners say that Lord Methuen began his advance to Kimberley on Nov. 22nd, 1899. Between this date and Dec. 11th there were four severe engagements, ending with the disastrous one at Magersfontein, all of which were productive of many wounded. Lord Methuen's force, according to the evidence of Surgeon-General Wilson, was accompanied by the full complement of bearer companies and field hospitals, each with a complete equipment, and before the advance Surgeon. General Wilson was told by the chief of the staff that the advance was only for the relief of Kimberley, which being accomplished the force would immediately return to its base. After the battle of Belmont, however, the principal medical officer, recognising the serious state of matters, telegraphed for some of the staff of No. 3 General Hospital and got up tents and equipment. No. 3 Stationary Hospital was sent up to De Aar and after Magersfontein two hospitals of the nature of stationary hospitals were established at Orange river and Modder river. These hospitals, which were more on the scale of field hospitals, were for a short time insufficiently supplied with certain articles such as bed-pans, and there was a shortage of orderlies. The hos pital trains, however, soon took the wousded down to Cape Town, so that there was never any considerable degree of pressure. The army remained at Magersfontein for two months-namely, from Dec. 11th, 1899, to Feb. 11th, 1900.

\section{Roberts's AdVANCE To Kimberley AND BLokmfontein.}

Lord Roberts left Ramdam on Feb. 12th, 1900, and Kimberley was relieved on Feb. 15th. Cronje's flight and eventual surrender at Paardeberg took up the time from Feb. 16 th to Feb. $27 \mathrm{th}$. The advance to Blcemfontein commenced on March 6th and after fighting at Poplar Grove and Driefontein Bloemfontein was reached on March 13 th. What happened during the advance from a medical point of view was as follows:-

When the advance of Lord Roberts's force for tbe relief of Kimberley was contemplated it was obvious that success depended on the mobility of the column of $\mathrm{r}$-lief, and in order to ensure mobility the transport bad to be reduced to a minjmum. The force was very deficient in mules and forage. The ordinary allowance for moving a division is 1666 mules and 416 oxen, whereas all the transport animals available for this column during its advance at this time were 946 mules and no oxen, and only four days' forage was available for the horses, mules. and oxen for the force. Sufficient forage even for the cavalry and mounted infantry could only be obtained by reducing the daily allow: ance from $12 \mathrm{lb}$. to $8 \mathrm{lb}$, and of course the force bad to provide for 